\title{
RADIOSENSITIVITY OF SUNFLOWER INBRED LINES TO MUTAGENESIS
}

Cvejić S. ${ }^{*}$, Afza R. ${ }^{2}$, Jocić S. ${ }^{1}$, Prodanović S. ${ }^{3}$, Miklič V. ${ }^{1}$,

Škorić D. ${ }^{4}$, Dragin, S. ${ }^{5}$

${ }^{1}$ Institute of Field and Vegetable Crops, Novi Sad, Serbia

${ }^{2}$ Joint FAO/IAEA Agriculture and Biotechnology Laboratory, Seibersdorf, Austria

${ }^{3}$ Faculty of Agriculture, University of Belgrade, Serbia

${ }^{4}$ Serbian Academy of Sciences and Arts (SASA), Branch in Novi Sad, Serbia

${ }^{5}$ Ministry of Agriculture, Belgrade, Serbia

Received: November 16, 2010 Accepted: March 15, 2011

\section{SUMMARY}

For much of the past century, mutagenesis has gained popularity in plant genetics research as a means of inducing novel genetic variation. Induced mutations have been applied for the past 40 years to produce mutant cultivars in sunflower by changing plant characteristics that significantly increase plant yield and quality. The present study is focused on generating baseline data to elucidate the role of genotypic differences in the response of sunflower to induced mutagenesis with the aim of expanding the applicability of the use of induced mutant stocks in the genetic improvement of the crop and in its functional genomics. The strategy adopted was to estimate the optimal treatment conditions (doses of mutagens) through relating the extent of damage in seedling progeny to the exposure levels of the initiating propagates to mutagens. Seeds of fifteen elite sunflower genotypes of commonly used as breeding stocks and grown on commercial scales were treated with a range of mutagens: gamma rays ( $\gamma$ rays); fast neutrons and with ethyl-methane-sulphonate (EMS) at different treatment doses. The three mutagenic agents affected seedling height, reducing it with increasing dosage. Based on the mutagen damage on seedling height, the $50 \%$ and $30 \%$ damage indices $\left(\mathrm{D}_{50}\right.$ and $\mathrm{D}_{30}$, respectively) were estimated for the 15 sunflower genotypes for the three mutagens. The $\mathrm{D}_{50}$ $\left(D_{30}\right)$ values for the sunflower lines ranged from 120 to 325 Gy (5 to $207 \mathrm{~Gy}$ ) for gamma irradiation; 9 to $21 \mathrm{~Gy}(0.1$ to $10 \mathrm{~Gy})$ for fast neutrons and 0.69 to $1.55 \%(0.01$ to $0.68 \%)$ concentration of EMS.

\section{Key words: sunflower, mutation, doses, gamma irradiation, fast neutrons, ethyl-methane-sulphonate}

* Corresponding author: Phone: ++381 214898 403; Fax: ++381 216413 833; e-mail: sandra.cvejic@ifvcns.ns.ac.rs 


\section{INTRODUCTION}

Sunflower (Helianthus annuus L.) is one of the world's most important oil crops, used for human consumption and industrial processes. It is also used as food, ornamental plant and flower, and as bird feed (Škorić, 1988). It is currently cultivated on over 23 million hectares world-wide annually (Faostat, 2009). The largest sunflower producers in the world are Russia, the United States, Argentina, China and France.

Induced mutations have been applied for the past 40 years to produce mutant cultivars in sunflower by changing plant characteristics for significant increase in plant productivity (Jain, 2005). Mutagenic treatments, usually on seed, have induced high-oleics, semi-dwarfs and dwarfs, male-sterile plants and other interesting variants such as earliness and seeds with thin hull (Voskoboinik et al., 1974; Miller \& Fick, 1997; Cvejić et al., 2009).

In 1976, Soldatov produced a mutant of significant practical importance for sunflower breeding by treating the seed of the cultivar VNIIMK 8931 with a solution of $0.5 \%$ dimethyl-sulphate (DMS); $\mathrm{M}_{3}$ lines possessing a high content of oleic acid in oil were obtained. After further breeding, the high-oleic cultivar Pervenetz was developed (Soldatov, 1976). The high oleic content of this cultivar has proved to be very stable under varying temperatures and the trait can be easily transferred into other genotypes by normal breeding procedures.

The main objectives of this research were to increase genetic variation in sunflower inbred lines and to assess the efficiency of different mutagenic treatments, since basic information on this is lacking. The first step was to estimate optimal treatment conditions (doses). Germination of the $\mathrm{M}_{1}$ seed provides a good test of the sensitivity of the material to the mutagenic treatment.

\section{MATERIALS AND METHODS}

Fifteen genetically different sunflower lines, all inbred and chosen for their importance in commercial hybrid production (Table 1) were used for this study. Seed of these genotypes varied morphologically. The Institute of Field Vegetable Crops, Novi Sad, Serbia, supplied the seeds.

\section{Three mutagenic agents were used:}

For gamma irradiation, 50 seeds of each genotype were irradiated at 100, 200, 300, 400 and 500 Gy using a Cobalt-60 gamma source at the IAEA Laboratories in Seibersdorf, Austria. Prior to mutagenic treatment, the seeds were kept in a desiccator over a $60 \%$ glycerol/water mixture for 7 days at room temperature for seed moisture equilibration.

For fast neutron treatment, 50 seeds were treated with five different doses: 10, 20, 30, 40 and 50 Gy at the Atomic Energy Research Institute, Budapest, Hun- 
gary. The samples were bombarded inside a cadmium $(\mathrm{Cd})$ capsule with wall thickness of $2 \mathrm{~mm}$. Exposure temperature was less than $30^{\circ} \mathrm{C}$, at normal air pressure and humidity was less than $70 \%$. The samples were rotated at 16 revolutions per minute. Ten days after the treatment, 25 seeds of each genotype were sown and germinated to assess radiosensitivity.

Table 1: List and characteristics of treated sunflower inbred lines

\begin{tabular}{|c|c|c|c|c|c|c|c|c|c|}
\hline Inbred lines & $\mathrm{T}$ & B & DF & $\mathrm{H}$ & 0 & SR & TSM & SC & SCT \\
\hline HA-26 & Standard female & no & 62 & 126 & 44 & 0.39 & 46.15 & black & thick \\
\hline VL-A-8 & Standard female & no & 65 & 108 & 47 & 0.5 & 48.42 & black & thick \\
\hline HA-48 & Standard female & no & 72 & 150 & 48 & 0.49 & 44.30 & black & thick \\
\hline HA-19 & Standard female & no & 56 & 80 & 47 & 0.53 & 50.70 & black & thick \\
\hline OD-3369 & Standard female & no & 71 & 105 & 55 & 0.42 & 52.16 & black & thick \\
\hline V-8931-OL & High oleic $(\mathrm{HO})$ & no & 63 & 95 & 54 & 0.47 & 47.47 & black & thin \\
\hline $\mathrm{HA}-26-\mathrm{OL}$ & High oleic & no & 65 & 119 & 47 & 0.40 & 51.96 & black & thick \\
\hline VK-66-tph & $\begin{array}{l}\text { Altered tocopherol } \\
\text { quality }\end{array}$ & yes & 57 & 75 & 41 & 0.42 & 46.28 & black & thick \\
\hline VK-66-tph $h_{1} t p h_{2}$ & $\begin{array}{l}\text { Altered tocopherol } \\
\text { quality }\end{array}$ & yes & 58 & 64 & 37 & 0.47 & 52.46 & black & thick \\
\hline VK-66-OL-tph $h_{2}$ & $\begin{array}{l}\mathrm{HO} \text { and altered } \\
\text { tocopherol quality }\end{array}$ & yes & 60 & 68 & 38 & 0.44 & 50.96 & black & thick \\
\hline RUS-RF-168 & Standard restorer & yes & 67 & 134 & 40 & 0.49 & 38.31 & black & medium \\
\hline RHA-SELEUS & Standard restorer & yes & 71 & 112 & 47 & 0.45 & 32.49 & brown & medium \\
\hline RHA-R-27 & Standard restorer & yes & 70 & 114 & 51 & 0.38 & 41.38 & brown & thin \\
\hline CMS-ANN-15 & Standard restorer & yes & 53 & 33 & 35 & 0.37 & 41.12 & black & thin \\
\hline RHA-S-OL-26 & High oleic restorer & yes & 69 & 88 & 55 & 0.38 & 28.43 & cream & medium \\
\hline
\end{tabular}

T-type of inbred line; B-branching; DF- days to flowering; H- Plant height (cm); O- Oil content (\%); SR-Seed size ratio; TMS- Thousand seed mass (g); SC- Seed color; SCT- Seed coat type

For chemical treatment, seeds were pre-soaked in distilled water for 24 hours. Twenty-five seeds of each genotype were treated with 5 concentrations of ethyl-methane-sulphonate (EMS) solution, 0.5, 1.0, 1.5, 2.0 and 2.5\%, for 3.5 hours; treatment concentrations were based on studies of other species (Kodym \& Afza, 2003). After EMS treatment, the seeds were washed and sown. The control, non-mutagenised seeds were treated similarly, except for exposure to the mutagen.

The treated seeds and the controls were sown in boxes in three replications using the flat method (Gaul, 1963) in a glasshouse under controlled environmental conditions $\left(22-35^{\circ} \mathrm{C}\right.$, lighting of $12 \mathrm{~h}$ photoperiod). The parameter used to assess the dose response was the seedling height. The measurements were taken when cotyledons emerged above the soil and had split up (12 days after sowing).

The mean seedling height of the control was used as an index of the normal growth of each inbred line. The mean seedling height of each treatment was expressed as a percentage of the corresponding control value. Based on these values, regression equations were obtained. Radiobiological effects of mutagenesis 
were observed in the $\mathrm{M}_{1}$, and calculated on the basis of the absorbed dose or EMS of the seedling height. According to (Brunner, 1995) and (Karma \& Brunner, 1977) seedling height reduction of $30-50 \%$ is generally assumed to give high mutation yield. Seedling height is highly proportionate to survival rate (Manual on Mutation Breeding, 1995). This is usually designated as $\mathrm{D}_{30}$ and $\mathrm{D}_{50}$, respectively.

\section{RESULTS AND DISCUSSION}

All seeds, the control and the irradiated ones, germinated. The seedling height in all three treatments decreased with increasing dose. For gamma irradiation the $\mathrm{D}_{50}$ and $\mathrm{D}_{30}$ values for the 15 sunflower inbred line seeds ranged from 120 Gy and 5 Gy, respectively for inbred line HA-19 to 325 Gy and 207 Gy, respectively for genotype VK-66-tph $h_{1}$. For fast neutron, the $\mathrm{D}_{50}$ and $\mathrm{D}_{30}$ for seeds of the 15 sunflower inbred lines seeds ranged from 9 Gy and 0.1 Gy, respectively (genotype HA-19) to 21 Gy and 10 Gy, respectively (genotype VK-66-tph $t_{1} t h_{2}$ ). The trend was therefore similar to the responses to gamma irradiation by these genotypes. The $D_{50}$ and $D_{30}$ values for these 15 sunflower inbred line seeds treated with EMS ranged from $0.69 \%$ and $0.01 \%$, respectively EMS concentration (genotype OD-3369) to $1.55 \%$ and $0.68 \%$, respectively for the line HA-19 (Table 2).

Table 2: $D_{50}$ and $D_{30}$ values for 15 inbreds for exposure to gamma rays, fast neutron bombardment and EMS solution

\begin{tabular}{lccccccccc}
\hline \multirow{2}{*}{ Genotypes } & \multicolumn{3}{c}{ Gamma rays (Gy) } & \multicolumn{3}{c}{ Fast neutrons (Gy) } & \multicolumn{3}{c}{ EMS (\%) } \\
\cline { 2 - 10 } & $\mathrm{D}_{50}$ & $\mathrm{D}_{30}$ & $\mathrm{~S}_{\mathrm{e}}$ & $\mathrm{D}_{50}$ & $\mathrm{D}_{30}$ & $\mathrm{~S}_{\mathrm{e}}$ & $\mathrm{D}_{50}$ & $\mathrm{D}_{30}$ & $\mathrm{~S}_{\mathrm{e}}$ \\
\hline HA-26 & 202 & 102 & 13.28 & 15 & 3.6 & 19.00 & 1.34 & 0.50 & 13.44 \\
VL-A-8 & 218 & 100 & 12.54 & 12 & 0.6 & 22.95 & 1.41 & 0.55 & 12.03 \\
HA-48 & 220 & 109 & 11.84 & 17 & 3.8 & 18.75 & 1.40 & 0.58 & 13.68 \\
HA-19 & 120 & 5 & 22.76 & 9 & 0.1 & 25.67 & 1.55 & 0.68 & 9.82 \\
OD-3369 & 151 & 18 & 20.34 & 11 & 0.1 & 24.56 & 0.69 & 0.01 & 22.39 \\
V-8931-OL & 155 & 44 & 15.96 & 13 & 1.5 & 21.21 & 0.82 & 0.07 & 22.95 \\
HA-26-OL & 181 & 76 & 13.39 & 12 & 1.0 & 22.27 & 1.16 & 0.43 & 14.16 \\
VK-66-tph & 325 & 207 & 9.03 & 20 & 9.0 & 15.50 & 1.41 & 0.53 & 13.75 \\
VK-66-tph tph $_{2}$ & 294 & 151 & 6.90 & 21 & 10.0 & 12.61 & 1.54 & 0.64 & 11.79 \\
VK-66-OL-tph & 289 & 164 & 3.45 & 19 & 8.0 & 16.14 & 1.36 & 0.55 & 14.78 \\
RUS-RF-168 & 201 & 101 & 14.33 & 20 & 7.3 & 20.86 & 1.09 & 0.30 & 14.88 \\
RHA-SELEUS & 206 & 95 & 13.43 & 15 & 2.6 & 21.80 & 1.15 & 0.39 & 12.40 \\
RHA-R-72 & 188 & 93 & 19.03 & 13 & 1.7 & 22.34 & 1.46 & 0.62 & 16.91 \\
CMS-ANN-15 & 237 & 146 & 14.89 & 13 & 0.4 & 20.52 & 0.94 & 0.25 & 13.51 \\
RHA-S-OL-26 & 197 & 79 & 12.89 & 14 & 2.0 & 15.11 & 1.36 & 0.50 & 16.17 \\
\hline
\end{tabular}

The data indicated that all genotypes produced a wide range of responses. With respect to radiation damage by gamma rays, the genotype HA-19 showed the least radiation damage with VK-66-tph ${ }_{1}$ displaying the highest damage. In the case of fast neutron, the genotype HA-19 was the most affected while VK-66-tph 1 and VK-66$t p h_{1} t p h_{2}$ had the least radiation damage. The study of EMS revealed OD-3369 to be 
least sensitive while VK-66-tph $h_{1} t p h_{2}$ again was highly susceptible. Reduction of seedling height was more pronounced in genotype HA-19 than any other genotype for both gamma and fast neutron irradiation and clearly demonstrated a genotypic response to mutagenic treatment. Interestingly, the same genotype showed the greatest resistance to high doses of EMS, inferring again a genotype - mutagen interaction. This line is very early maturing and it has round and large seed. Lines OD3369 and V-8931-OL were generally more sensitive to all three mutagens than the others. These inbreeds have very high oil contents in the seed, have normal sized seeds and high thousand seed mass. Inbred lines VK-66-tph , VK-66-tph $_{1} t p h_{2}$ and

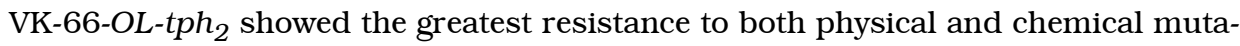
genic treatments. These genotypes are nearly isogenic lines, with different oil quality but low oil quantity. They have large, dark black seeds but a thick coat which is probably the reason for such high resistance to mutagenic treatments.

The three mutagenic agents affected seedling height, reducing it with increasing dosage. Based on the mutagen damage on seedling height, the $\mathrm{D}_{50}$ and $\mathrm{D}_{30}$ values for 15 sunflower genotypes were estimated for the three mutagens. Retardation of growth due to the mutagenic treatments has been used to determine the dose rate for mutation induction. It is the most functional parameter which has been used in radiobiological investigations because it is generally considered to be a result of primary injury due to nuclear DNA damage. Sensitivity in seedlings height had been demonstrated in earlier dose response studies of bean (Cheah \& Lim, 1982), soybean (Koo et al., 1972), and other crops.

In this experiment, we established relationships between the $\mathrm{D}_{50}$ values due to gamma and fast neutron irradiation and EMS to the thousand seed mass, seed size ratio, oil content in the seed, plant height and days to flowering (Table 3). A significant negative correlation was found between the treatment and seed oil content, indicating that genotypes with relatively high seed oil content were more sensitive to gamma irradiation, fast neutrons and EMS. Also, larger seeds were generally more resistant to EMS treatment than to gamma and fast neutron irradiation. There was a negative correlation between early flowering, short stature plants and gamma irradiation. Mutagenic damage depended on the biological traits of the variety.

Table 3: Correlations between biological traits and response to mutagenic treatments

\begin{tabular}{lccc}
\hline Biological traits & Gama rays & Fast neutrons & EMS \\
\hline Thousand seed mass & 0.15 & 0.00 & 0.14 \\
Seed size ratio & -0.17 & -0.18 & $0.38^{\star}$ \\
Oil content & $-0.69^{\star *}$ & $-0.37^{\star}$ & $-0.39^{*}$ \\
Plant height & $-0.39^{\star}$ & -0.20 & 0.11 \\
Days to flowering & $-0.41^{*}$ & -0.14 & -0.24 \\
\hline
\end{tabular}

$\mathrm{r}(0.05)=0.349 \quad \mathrm{r}(0.01)=0.449$

The results obtained from this study indicated that the radiation damage due to mutagenic treatment was not similar amongst the genotypes. The same differential 
responses to radiation among different genotypes in plant species was reported by many researchers. These inter-varietal differences in radiation damage to seeds have been reported to be: a) under polygenic system in rice, tomato and barley (Ukai, 1967; Davies, 1962a,b; Ukai \& Yamashita, 1969; Kowyama et al., 1987); b) major gene control in einkorn wheat and soybean (Smith, 1942; Takagi, 1969) and c) influenced by heterozygosity in maize and peanut (Notani, 1961; Stoilov et al., 1966; Emery et al., 1970). It is widely accepted that response to mutagens is species and genotype dependent, but the full explanation has not yet been provided.

\section{CONCLUSION}

The different $\mathrm{D}_{50}\left(\mathrm{D}_{30}\right)$ values for sunflower inbreds were established: dose range of 120 to 325 Gy ( 5 to $207 \mathrm{~Gy}$ ) for gamma irradiation, 9 to 21 Gy $(0.1$ to 10 Gy) for fast neutrons irradiation and 0.69 to $1.55 \%(0.01$ to $0.68 \%)$ concentration of EMS. The radiation sensitivity studies indicated that all the genotypes treated exhibited a wide range of radiation damage to gamma rays and fast neutrons.

Based on the radiation damage, bulk irradiation with a dose giving rise to a $30 \%$ to $50 \%$ reduction in growth will be carried out and $M_{1}$ plants will be grown in the field. Different mutations will be observed in the field and promising mutants will be selected for further testing. Selection will be carried out in the $\mathrm{M}_{2}$ generation for the following: early flowering, short stature, deformations of leaves and heads, appearance of branches, head inclination, sterility and oil seed quantity and quality.

\section{REFERENCES}

Brunner, H., 1995. Radiation induced mutations for plant selection. App. Radiat. Isot. 46: 589594.

Cheah, Ch., Lim, E.S., 1982. Mutagenesis applied to the improvement of Phaseolus vulgaris as a grain legume crop in Malaysia. Induced mutation s for improvement of grain legumes production II. IAEA TECDOC-260, Vienna. 109-116.

Cvejić, S., Prodanović, S., Jocić, S., 2009. Enhancement of genetic variability for the seed oil composition by induced mutations in sunflower collection. $19^{\text {th }}$ EUCARPIA Conference. Genetic Resources Section, Book of Abstracts, Ljubljana, Slovenia, May 26-29th, p.p. 75.

Davies, D.R., 1962a. The genetical control of radiosensitivity-I. Seedling characters in tomato. Heredity 17: 63-74.

Davies, D.R., 1962b. The genetical control of radiosensitivity-II. Growth measurements in Lycopersicum and Melandrium. Radiat. Bot. 1: 277-295.

Emery, D.A., Boardman, E.G., Stucker, R.E., 1970. Some observations on the radiosentitivity of certain varietal and hybrid genotypes of cultivated peanuts (Arachis hypogaea L.). Radiat Bot. 10: 269-272.

Faostat, 2009. Available online at: http://www.faostat.org (16.11.2010)

Gaul, H., 1963. Mutationen in der Pflanzenzuhtung. Z. Pflanzenzuecht. 50: 194-307.

Jain, S.M., 2005. Major mutation- assisted plant breeding programs supported by FAO/IAEA. Plant Cell, Tissue and Organ Culture 82: 113-123.

Karma, O.P., Brunner, H., 1977. Chemical mutagens: dose. In: Manual on Mutation Breeding. IAEA Technical Reports Series, $2^{\text {nd }}$ ed. 119: 66-69.

Kodym, A., Afza, R., 2003. Phisical and Chemical Mutagenesis. In: Grotewold [ed.] Plant Functional Genomics. Humana Press, Inc., Totowa, NJ, 236: 189-203. 
Koo, F.K.S., Ferror-Monge, J.A., Otero, A.K., Abulla, I., Almany, A., 1972. Effect of fast neutron and gamma rays on soybean seedling growth and malatedehydrogenase isozyme pattern after seed irradiation. Neutron irradiation of seed. III. Technical report series, IAEA, Vienna, 141: 95-103.

Kowyama, Y., Saito, M., Kawase, T., 1987. Absence of storage sffects on radiation damage after thermal neutron irradiation of dry rice seeds. Japan J. Breed. 37: 301-310.

Manual on Mutation Breeding. 1995. International Atomic Energy Agency, Vienna, p. 1-91.

Miller, J.F., Fick, G.N., 1997. The Genetics of Sunflower. In: Schneiter, A. A. [ed.] Sunflower Technology and Production p.p. 395-439.

Notani, N.K., 1961. A study of differences in the radiosensitivity of some inbreds and hybrids in maize. In: Effects of ionizing radiations on seeds. IAEA, Vienna, 475-484.

Škorić, D., 1988. Sunflower breeding. Journal of Edible Industry, Uljarstvo 25: 3-75.

Smith, L., 1942. Hereditary susceptibility to X-ray injury in Triticum monococcum. Am. J. Bot. 29: 189-191.

Soldatov, K.I., 1976. Chemical mutagenesis in sunflower breeding. In: Proc. $7^{\text {th }}$ Int. Sunflower Conf., Krasnodar, USSR. 27 June-3 July 1976. Int. Sunflower Assoc., Vlaardingen, the Netherlands, 352-357.

Stoilov, M., Jansson, G., Eriksson, G., Ehrenberg, L., 1966. Genetical and physiological causes of the variation of radiosensitivity in barley and maize. Radiat. Bot. 6: 457-467.

Takagi, Y., 1969. The second type of gamma sensitive gene RS2 in soybean Glycine max (L.) Merrill. Gamma Field Symp. 8: 83-94.

Ukai, Y., 1967. Studies on varietal differences in radiosensitivity in rice -I Dose response curve for root growth and varietal difference in radiosensitivity. Japan J. Breed. 17: 33-36.

Ukai, Y., Yamashita, A., 1969. Varietal differences in radiosensitivity with special reference to different aspects with different crops. Gamma Field Symp. 8: 69-81.

Voskoboinik, L.K., Soldatov, K.I., 1974. The research trends in the field of sunflower breeding for heterosis at the All-Union Research Institute for Oil Crops (VNIIMK). In: Proc. $6^{\text {th }}$ Intl. Sunflower Conf., Bucharest, Romania, 22-24 July 1974. Intl. Sunflower Assoc., Paris, France. P.p. 383-389. 
